\title{
MURRAY VALLEY ENCEPHALITIS (AUSTRALIAN ENCEPHALITIS)
}

\section{WHAT IS MURRAY VALLEY ENCEPHALITIS ?}

- Murray Valley encephalitis (MVE) is a potentially fatal mosquito-borne disease caused by the Murray Valley encephalitis virus.

- It is also known as Australian encephalitis.

\section{WHERE DOES THE DISEASE OCCUR?}

- MVE usually occurs in remote north western Australia. It rarely occurs in eastern Australia.

- To date (May 2001), there have been no human cases in south eastern Australia-including NSW and Victoria-reported since 1974.

- In previous outbreaks, the virus affected people living in western NSW.

\section{HOW IS THE DISEASE SPREAD?}

- MVE virus is spread by the bite of a mosquito that is infected with the virus.

- Not all mosquitoes carry the virus.

- The most common species to carry the virus is Culex annulirostris. Only one person in about one thousand will acquire the disease after being infected through a mosquito bite.

- The virus is carried by water birds. Mosquitoes become infected by biting birds or other animals that carry the virus. Spread to south eastern Australia is thought to occur with waterbird migration that follows unusually wet conditions in inland Australia.

\section{WHO IS MOST AT RISK?}

- The disease is fatal in about 20 per cent of those who become sick, and a further 25 per cent can develop major intellectual and/or neurological complications. About 40 per cent of cases will make a complete recovery.

\section{WHAT ARETHE SYMPTOMS?}

- The disease takes about of 5-15 days to develop following the bite of an infected mosquito.

- The great majority of people infected with MVE will have no symptoms. Of those who do, symptoms may include:
- severe headache

- neck stiffness

- fever

- tremors

- seizures (particularly in young children)

- confusion

— vomiting

- nausea

- diarrhoea

- dizziness

- lethargy, irritability, drowsiness

- coma (in severe cases).

- People experiencing these symptoms should seek medical attention.

\section{PREVENTION}

There is no specific treatment or vaccine available for MVE. The only protection is to avoid being bitten by mosquitoes. This is particularly important to travellers and visitors to areas where MVE might be active.

\section{PROTECT YOURSELF FROM MOSQUITOES}

Mosquito protection during periods of MVE activity is absolutely essential:

- Avoid being outside when mosquitoes are most active, particularly early in the morning and from just before sunset to mid-evening.

- Wear loose fitting light coloured clothing with long sleeves, long trousers and socks. Mosquitoes can bite through tight fitting clothes.

- Use insect repellent when outdoors and reapply when appropriate. Lotions and gels are more effective and longer lasting than sprays.

- Make sure flyscreens and doors are in good order, if camping out sleep under a mosquito net or in a mosquito-proof tent.

- Use a 'knock down' insect spray before going to bed to kill any mosquitoes that are indoors.

For further information contact your doctor, community health care centre or your nearest Public Health Unit.

April 2001.

\section{NSWNㅠHEALTH}

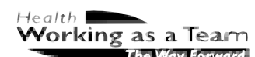

\section{COMMUNICABLE DISEASES, NSW: APRIL 2001}

\section{TRENDS}

Highlights of communicable diseases notifications in NSW through to February 2001 include continuing declines in pertussis, measles and rubella, and continuation of the seasonal rise in arboviral infections, due to Ross River and Barmah Forest viruses (Figure 8, Table 14). 